\title{
AGING DEGRADATION OF Ni AND NiCr-Ni THIN FILM CONDUCTOR SYSTEMS
}

\author{
A. GORECKA-DRZAZGA and D. MUSZYNSKA \\ Institute of Electron Technology, Technical University of Wroclaw, Poland
}

(Received July 7, 1981; in final form October 20, 1981)

\begin{abstract}
In this paper an experimental procedure for the evaluation of the $\mathrm{Ni}$ and $\mathrm{NiCr}-\mathrm{Ni}$ new low cost conductor systems is described. The possibility of an application of these conductor systems as a contact material for thin film resistors has been examined. A special test pattern with intermittent pattern resistors and meander patterns of conductor and resistive material was applied. The quality of thin film resistor contacts is defined by the constancy of their electrical and physical properties during exploitation. Following the R.T. Galla distributed parameter analysis model the calculation of the aging degradation of the $\mathrm{Ni}$ and $\mathrm{NiCr}-\mathrm{Ni}$ conductor systems has been carried out.

Considering the degradation values it seems that the $\mathrm{Ni}$ one-component conductor system is superior to the $\mathrm{NiCr}-\mathrm{Ni}$ two-component system. From this investigation we can conclude that the quality of studied conductor systems is satisfactory in applications where corrosion resistance is not critical.
\end{abstract}

\section{INTRODUCTION}

Major requirements for the contact material of thin film resistors are:

- Low sheet resistance,

- Resistance to corrosion,

- Bondable top surface,

- Adherence to the substrate surface,

- Compatibility with processing of other film components.

Generally, these requirements are not met by any one material. Thus, the contact material used in thin film technology consists of multiple layers of different metals which form a conductor system. A thin film conductor system can be a one, two, three or four component system. Considering a three-component system, the first film (e.g. titanium) is used for adherence to the substrate surface purposes, the second (e.g. palladium) protects the first film from corrosion and the third film (e.g. gold) provides the conductivity and bondability. It is desirable to use the smallest number of metals in order to simplify the technological process.

The one-component system (e.g. Al) seems to be of best advantage where corrosion resistance is not critical. Recently, nickel thin films were investigated by $\mathrm{S}$. Abdin and others as a new one-component conductor system and they obtained satisfying results. ${ }^{3}$

Up to now, a nickel thin film has been used as a component of a low cost $\mathrm{Ti}-\mathrm{Cu}-\mathrm{Ni}-\mathrm{Au}$ conductor system. ${ }^{2}$ The introduction of a $\mathrm{Cu}-\mathrm{Ni}$ interlayer enables a reduction of the gold film thickness to be made. Nickel is a barrier to the diffusion of copper to the gold surface. In addition to its role as a diffusion barrier, nickel also acts as a corrosion inhibitor like $\mathrm{Pd}$ in the Ti-Pd-Au system. ${ }^{1}$

This paper describes an analytical technique for the evaluation of the $\mathrm{Ni}$ and $\mathrm{NiCr}-\mathrm{Ni}$ conductor systems as contact materials for thin film resistors.

\section{ANALYSIS}

The quality of a contact for a thin film resistor is defined by its electrical and physical degradation during its exploitation. The resistance of contacts depends on oxidation, recrystallization, interdiffusion and defects which are activated by temperature or electrical field. It can also be affected by the diffusion of species from air to the interface between the resistive $\left(\mathrm{e} . \mathrm{g} . \mathrm{Ta}_{2} \mathrm{~N}\right)$ and the adherence layer. The type and rate of this corrosion can depend on the amount of minor constituents such as water and chlorine present in the air. ${ }^{4}$

The resistance of a thin film resistor can be considered as consisting of three parts: the resistance of the resistive material, the resistance of the conductor layer and the interfacial resistance. The contribution of the interfacial resistance can be described by a R.T. Galla distributed parameter (Figure 1) analysis model. ${ }^{5}$ It is assumed that the interfacial resistance can be represented by a uniform layer of resistive material characterized by its specific through-conductance $G\left[\mathrm{mho} / \mathrm{mm}^{2}\right]$. The sheet resistances of the resistive material and of the conductor system are $R_{s}$ and $\bar{R}_{s}$, respectively. Following the J.S. Fisher 

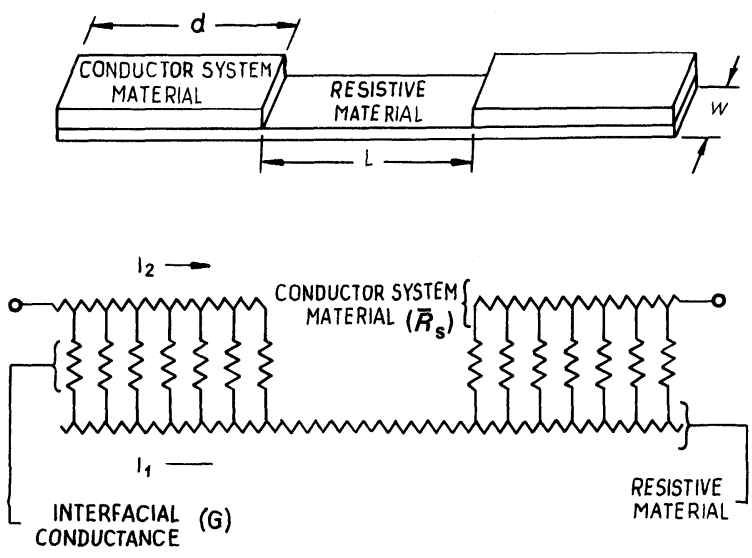

FIGURE 1 Model of a very short resistor, showing the distributed interfacial resistance. ${ }^{1}$

adaptation of an analysis by R.T. Galla, the resistance of the model is made up of three terms ${ }^{1}$

$$
R=R_{s}\left(\frac{L}{w}\right)+\bar{R}_{s}\left(\frac{2 d}{w}\right)\left(1+\frac{\bar{R}_{s}}{R_{s}}\right)^{-1}+R_{I}
$$

Where $L$ is the length of the resistor, $d$ the length of the conductor at one end and $w$ the width. The first term represents the main body of the resistor. The second term is from the parallel combination of the conductor system and the resistive material over the length of the contact. The third term is the interfacial resistance and it is also inversely proportional to the width. The last term can be calculated exactly by J.S. Fisher's analysis for a distributed interfacial resistance. ${ }^{1}$ This gives that:-

$$
R_{I}=\frac{2}{w}\left(\frac{R_{s}}{G}\right)^{1 / 2}
$$

when $R_{s} \gg \bar{R}_{s}$. All three of the terms in Eq. 1 contribute to the aging. The total aging of the resistor is expressed as the relative change in its resistance and is found from Eqs. 1 and 2 by taking $\Delta R$ and normalizing by $R_{s} L / w$

$$
\frac{\Delta R}{R}=\frac{\Delta R_{s}}{R_{s}}+\frac{2 d}{L} \frac{\Delta \bar{R}_{s}}{R_{s}}+\frac{2}{L \sqrt{ } R_{s}} \Delta\left(G^{-1 / 2}\right)
$$

The three terms in Eq. 3 represent the three contributions to the aging:
- the increase in the resistive material sheet resistance,

- the change in the conductor system layer sheet resistance,

- the increase in the interfacial resistance.

The effect of conductor system-aging can be separated from the effect of the aging of a resistor in real applications by combining Eq. 3 with the experimental results. In this paper the degradation of conductor systems as a function of temperature and time exposure in air is examined.

\section{EXPERIMENTAL}

Effects of $\Delta R / R$ and $\Delta R_{I}$ should be measured on very short resistors. ${ }^{1,4}$ The low resistance value of a short resistor is not measurable as accurately as of a long resistor. Thus, it is necessary to measure a large number of very short resistors in series. The pattern chosen for this study contains 40 such resistors. Each resistor consists of one square $(0.25 \mathrm{~mm}$ by $0.25 \mathrm{~mm})$ of resistive material and 3 squares $(0.75 \mathrm{~mm}$ by $0.25 \mathrm{~mm}$ ) of conductor system material. The resultant pattern is shown in Figure 2. Each studied test pattern contains two intermittent pattern resistors such as the one shown in Figure 2 for resistance measurements, one long meander resistor of resistive material to measure $\Delta R_{s} / R_{s}$, one meander pattern of conductor system material to measure $\Delta \bar{R}_{s}$ and eight bonding pads used only for adhesive measurements.

Several types of the thin film combinations have been studied using this pattern and analysis. These are: $\mathrm{Ta}_{2} \mathrm{~N}-\mathrm{Ni}, \mathrm{NiCr}-\mathrm{Ni}, \mathrm{Ta}_{2} \mathrm{~N}-\mathrm{NiCr}-\mathrm{Ni}$, where $\mathrm{NiCr}$ indicates an alloy of roughly 80 percent $\mathrm{Ni}$ and 20 percent $\mathrm{Cr}$. In these experiments the nickel films were deposited by electron gun evaporation onto multiform glass (sital CT-50) substrates immediately following the deposition of the $\mathrm{Ta}_{2} \mathrm{~N}$ or $\mathrm{NiCr}$. The thicknesses of conductor system layers $\mathrm{Ni}$ and $\mathrm{NiCr}$ were $400 \mathrm{~nm}$ and $60 \mathrm{~nm}$, respectively. After the pattern was etched, the intermittent pattern resistors, the long resistors and the conductor system paths were measured for resistance. Finally the substrates were aged at $250^{\circ} \mathrm{C}$ for 5 hours in air. Measurements

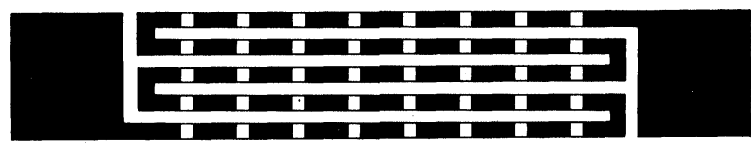

FIGURE 2 Intermittent pattern, consisting of 40 resistors in series, each one "square" long. 
at two different aging temperatures, 150 and $250^{\circ} \mathrm{C}$, for up to 1000 hours were carried out.

\section{DISCUSSION}

The possibility of the application of $\mathrm{Ni}$ and $\mathrm{NiCr}-\mathrm{Ni}$ conductor systems as a contact material for thin film resistors has been examined. The work reported here was all carried out on tantalum nitride and nichrome film resistors. The evaluation of the studied conductor systems was carried out on the accelerated aging measurements of the resistance change of the long resistor $\Delta R_{s}$ the conductor system resistor, $\Delta \bar{R}_{s}$ and the intermittent pattern resistor, $\Delta R$. The results of aging $\mathrm{Ta}_{2} \mathrm{~N}$ and $\mathrm{NiCr}$ resistors and the intermittent pattern for $\mathrm{Ta}_{2} \mathrm{~N}-\mathrm{Ni}, \mathrm{Ta}_{2} \mathrm{~N}-\mathrm{NiCr}-\mathrm{Ni}, \mathrm{NiCr}-\mathrm{Ni}$ at 150 and $250^{\circ} \mathrm{C}$ in air up to 1000 hours are shown in Figure $3(\mathrm{a}-\mathrm{c})$. The aging of the intermittent pattern resistor closely approximates to that of the long resistor. Because the resistors age at the same rate, aging of $\mathrm{Ni}$ and $\mathrm{NiCr}-\mathrm{Ni}$ conductor system layers does not introduce any detectable resistance changes.

However this qualitative evaluation is not sufficient.

Following J.S. Fisher's analysis a quantitative estimation of degradation of the conductor systems
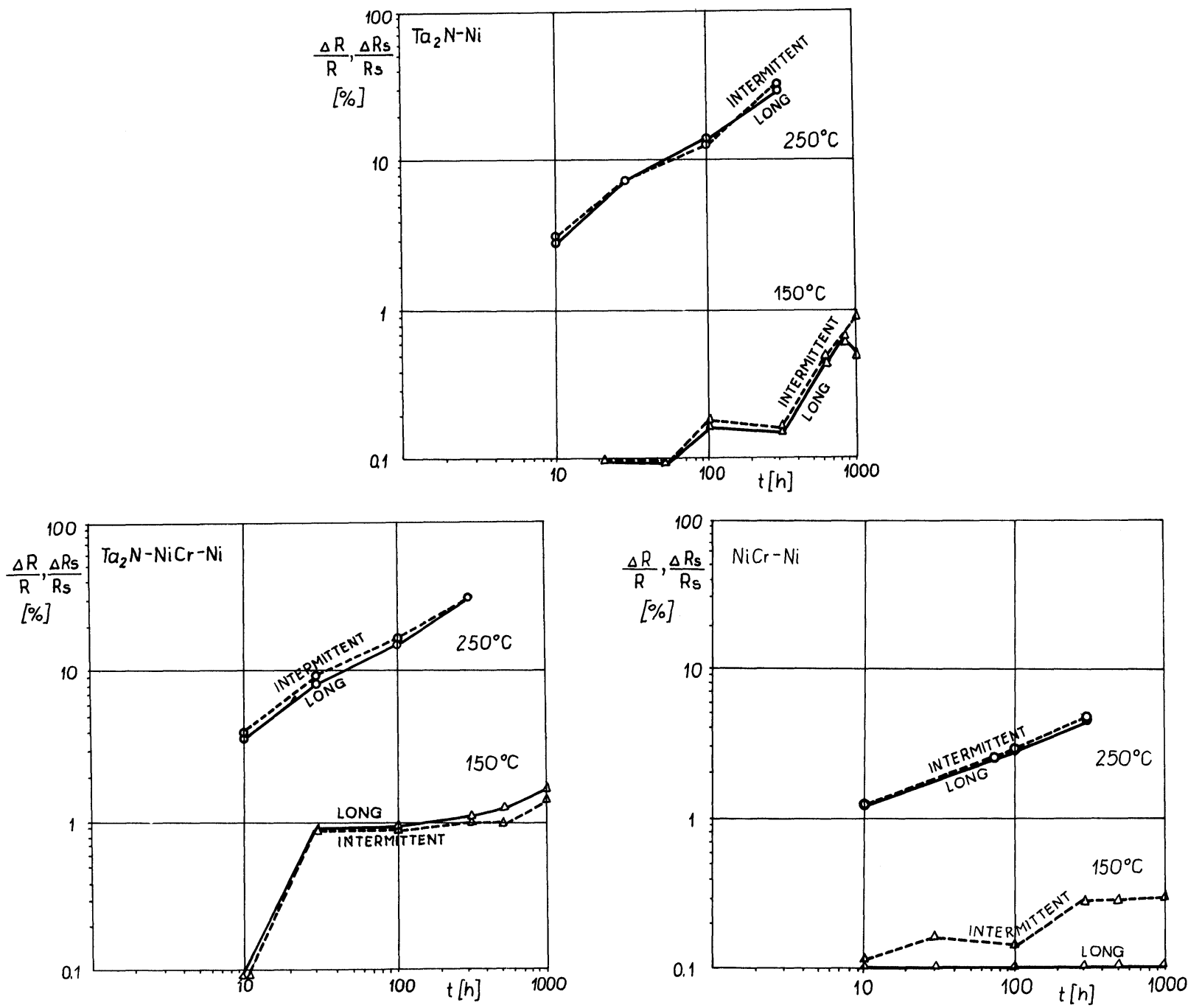

FIGURE 3 Resistance changes during oven aging at 150 and $250^{\circ} \mathrm{C}$ vs, time for a) $\left.\mathrm{Ta}_{2} \mathrm{~N}-\mathrm{Ni}(30 \mathrm{~nm} / 400 \mathrm{~nm}) \mathrm{b}\right) \mathrm{Ta}{ }_{2} \mathrm{~N}-\mathrm{NiCr}-\mathrm{Ni}$ $(30 \mathrm{~nm} / 60 \mathrm{~nm} / 400 \mathrm{~nm}) \mathrm{c}) \mathrm{NiCr}-\mathrm{Ni}(20 \mathrm{~nm} / 400 \mathrm{~nm})$. 
under study has been carried out. This degradation can be defined as the value of the third term Eq. 3 .

In our calculation it was considered that the resistance stability of $\mathrm{Ni}$ was different from the stability of the $\mathrm{NiCr}-\mathrm{Ni}$ conductor system (Figure 4). It is clear, that the phase order of the Ni one-component system predominates over the oxidation effect. A passive nickel oxide layer has formed during the heat treatment ${ }^{3}$ which protects the film from further oxygen diffusion. However the oxidation effect was the essential aging mechanism for the $\mathrm{NiCr}-\mathrm{Ni}$ two component system. Probably, $\mathrm{Cr}$ diffuses through the $\mathrm{Ni}$ layer and can be oxidized. This process ends when all the $\mathrm{Cr}$ is transported. ${ }^{6}$ Thus, it would appear that a nickel thickness of about $400 \mathrm{~nm}$ is not effective as a barrier to the diffusion of $\mathrm{Cr}$ on the Ni surface.

A similar effect in the Ti-Cu-Ni-Au system has also been observed by J.M. Morabito. ${ }^{2}$

Ordering effects, oxidation and interdiffusion in conductor systems influence their quality. To quan-
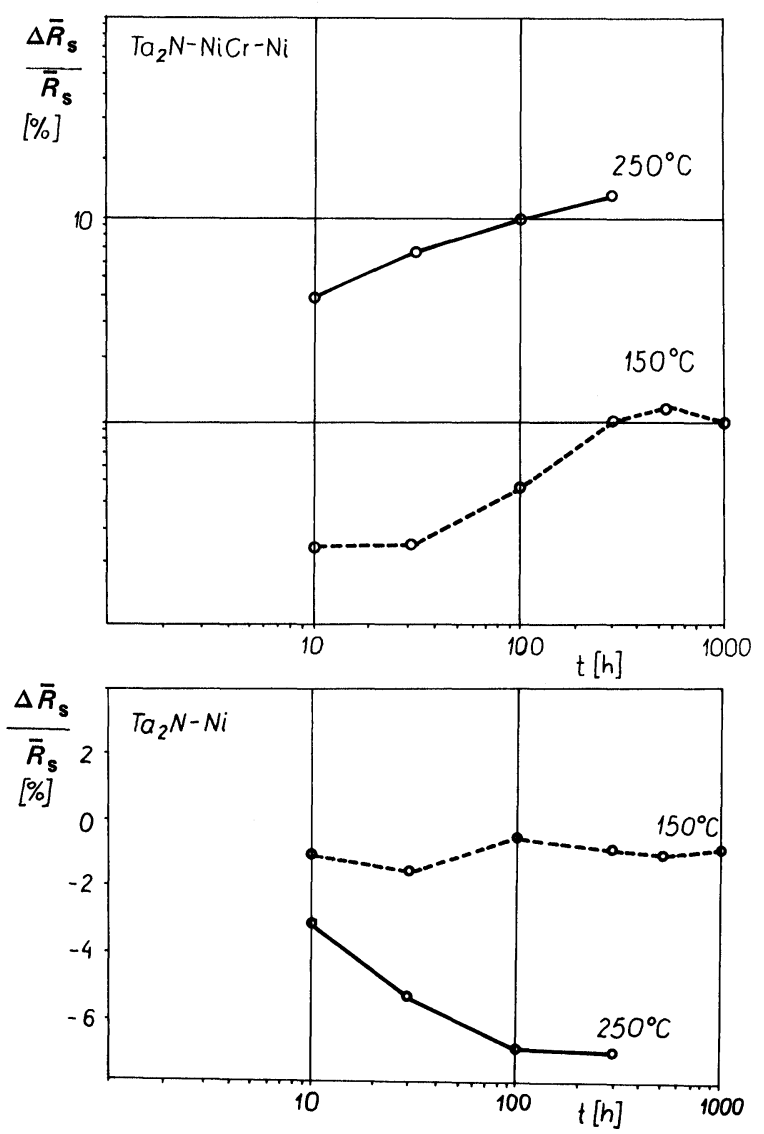

FIGURE 4 Oven aging of conductor systems at 150 and $250^{\circ} \mathrm{C}$. titatively evaluate the conductor systems, the timetemperature stability of the components, were analysed which enabled the value of degradation

$$
A=\frac{2}{L \sqrt{ } R_{s}} \Delta\left(G^{-1 / 2}\right)
$$

of the system to be calculated from Eq. 3. The calculated values of degradation " $A$ " are plotted against annealing time in Figure 5. The $\mathrm{Ta}_{2} \mathrm{~N}-\mathrm{Ni}$ system shows the lowest degradation at $150^{\circ} \mathrm{C}$ aging temperature as well as at $250^{\circ} \mathrm{C}$. In the case of the $\mathrm{Ta}_{2} \mathrm{~N}-\mathrm{NiCr}$
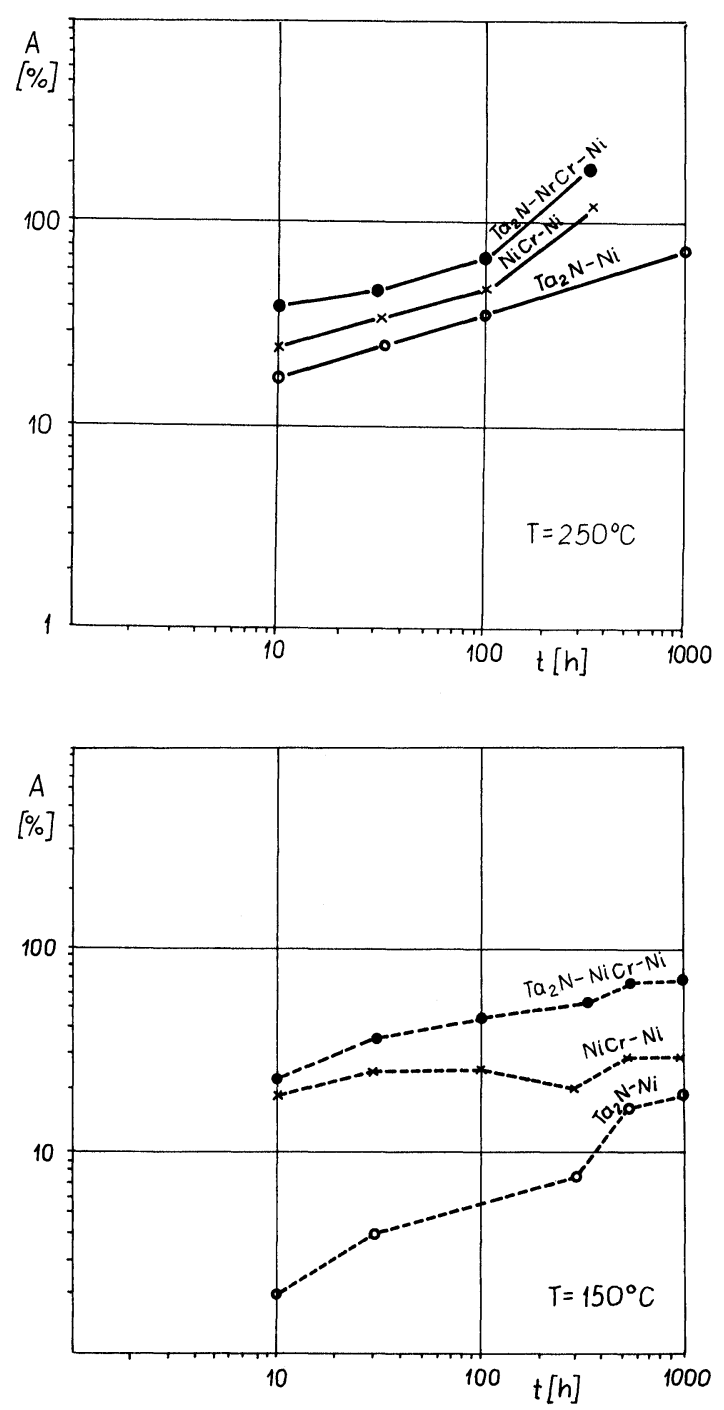

FIGURE 5 Aging degradation of conductor systems vs. time. 
$\mathrm{Ta}_{2} \mathrm{~N}-\mathrm{NiCr}-\mathrm{Ni}$ system, the worse properties were observed.

On the $\mathrm{NiCr}-\mathrm{Ni}$ and $\mathrm{Ni}$ layers adhesion measurements have been carried out using the wire peel test. Each test substrate had eight conductor system pads $\left(1 \mathrm{~mm}^{2}\right)$. In this method the bonding pads were coated with $\mathrm{Sn}-\mathrm{Pb}$ solder alloy using a special solder flux and phosphor bronze wires were soldered on. The measurements were made on a tensile testing machine. For both systems the breaking strength was about $20 \mathrm{~N} / \mathrm{mm}^{2}$.

On measuring the adhesion strength it was not observed that the solder pad and Ni layer came off the $\mathrm{NiCr}$ or $\mathrm{Ta}_{2} \mathrm{~N}$ layers. In many cases the forces of adhesion were larger than the forces of substrate cohesion.

\section{CONCLUSION}

1) The calculation of the aging degradation allows evaluation of the quality of the conductor system.

2) Considering the degradation values it would appear that the Ni one-component conductor system is superior to the $\mathrm{NiCr}-\mathrm{Ni}$ two-component system.

3) A nickel thickness of about $400 \mathrm{~nm}$ is not effective as a barrier to the diffusion of $\mathrm{Cr}$ to the $\mathrm{Ni}$ surface, but the increase of the Ni thickness can improve the properties of the $\mathrm{NiCr}-\mathrm{Ni}$ conductor system.

4) Adhesion and solderability of $\mathrm{Ni}$ and $\mathrm{NiCr}-\mathrm{Ni}$ conductor systems are satisfactory.

5) From this investigation we can conclude that the quality of the $\mathrm{Ni}$ and $\mathrm{NiCr}-\mathrm{Ni}$ conductor systems is satisfactory in applications where corrosion resistance is not critical.

\section{REFERENCES}

1. J.S. Fisher and P.M. Hall, 'Termination Materials for thin film resistors'. Proc. IEEE, 59, p 1418 (1971).

2. J.M. Morabito, 'Material characterization of $\mathrm{Ti}-\mathrm{Cu}-\mathrm{Ni}-\mathrm{Au}-\mathrm{a}$ new low cost thin film conductor system'. IEEE, Trans. PHP-11, 4, p 253 (1975).

3. S. Abdin and A. Huber, 'Properties of nickel films prepared by sputtering and interdiffusion analysis of $\mathrm{Ta}_{2} \mathrm{~N}-\mathrm{Ni}$ films'. Proc. European Hybrid Microelectronics Conf., Ghent, Belgium p 205 (1979).

4. F.N. Fuss, C.T. Hartwig and J.M. Morabito, 'Corrosion of solder-coated TiPdAu thin film conductors in a moist chlorine atmosphere'. Thin Solid Films, 43, p 189 (1977).

5. R.T. Galla, H.M. Greenhouse and W.C. Vergara, 'Evaluation of the interfacial resistance of thin film interconnexions'. Microelectron. Reliab. 7, p 185 (1968).

6. A. Scatamacchia and G. Ottaviani, 'Interdiffusion processes and oxidation phenomena in $\mathrm{NiCr} / \mathrm{Au}$ films'. Solid State Technol., February p 116 (1980). 

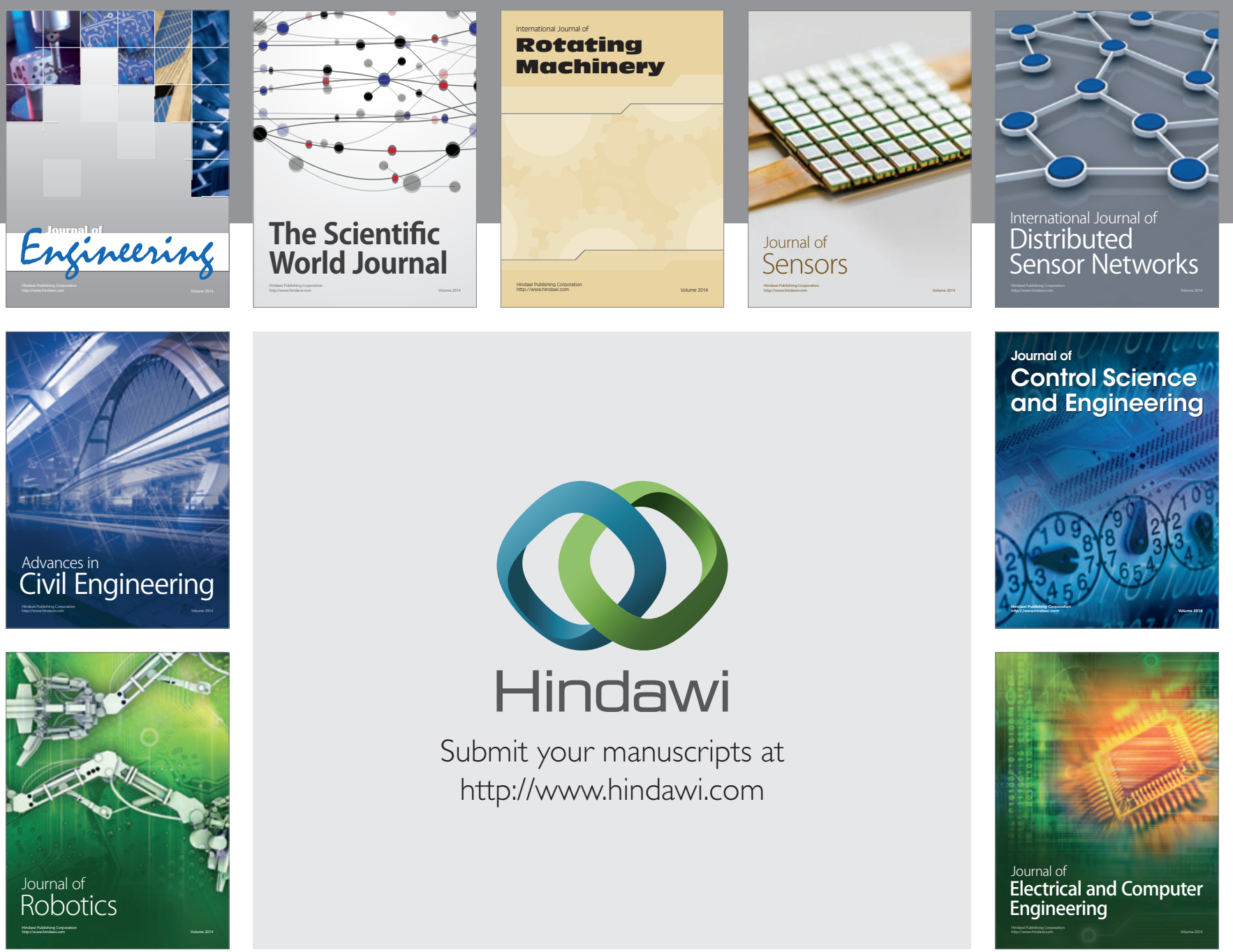

Submit your manuscripts at

http://www.hindawi.com
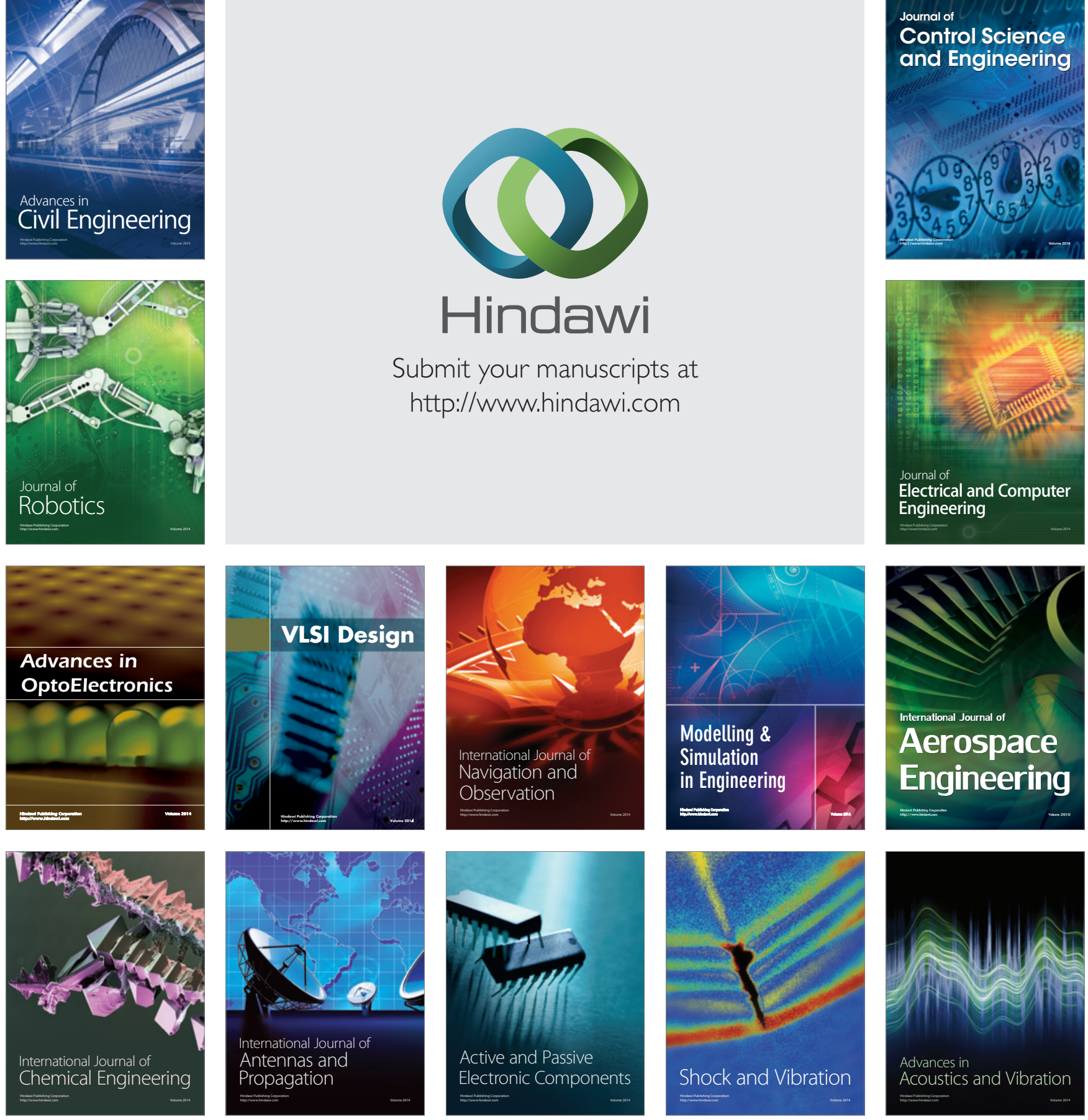